\title{
Late-onset jaw and teeth pain mimicking trigeminal neuralgia associated with chronic vagal nerve stimulation: case series and review of the literature
}

\author{
Gabriela Timarova ${ }^{1 *}$ (i) and Andrej Šteňo ${ }^{2}$
}

\begin{abstract}
Background: Vagal nerve stimulation (VNS) for refractory epilepsy is well established. Trigeminal neuralgia itself is a common disease in adults, and thus, late-onset pain in the trigeminal region under VNS, which is extremely rare, may not be recognized as caused by VNS.

Case presentation: Two patients with drug-resistant symptomatic epilepsy treated with chronic VNS experienced stimulation-related pain in the lower and upper jaw and teeth on the side of stimulation. No evidence of local spread of the stimulation current was present. The pain started with a delay of years after device implantation and weeks after the last increase in the pacing parameters. At the time of onset, the pain was not recognized as VNS-related, leading to extensive examinations. The trigeminal neuralgia-like pain resolved after adjustment of the stimulation current intensity. In one of the patients, the pain disappeared within one to two days following every epileptic seizure. To our knowledge, this is the first case report of late-onset trigeminal pain under VNS revealing a direct link between epileptogenic and pain processes.

Conclusion: A painless interval between the last change of the pacing parameters and trigeminal pain can lead to the erroneous interpretation that this is a typical trigeminal neuralgia. The lack of its recognition as a side effect of VNS can lead to unnecessary examinations and delayed adjustment of stimulation parameters. In patients with signs of late-onset trigeminal pain under VNS with normal electrode impedance and no evidence of local current spread, the replacement of the VNS lead does not seem to be beneficial. A review of the literature on VNS side effects including pain and device malfunctions was undertaken.
\end{abstract}

Keywords: VNS, Epilepsy, Trigeminal pain, Side effects, Pain, Case report

\section{Background}

Vagal nerve stimulation (VNS), delivered by the NCP System (Cyberonics, Houston, TX, USA) for treatment of drug-resistant epilepsy is approved as an add-on therapy in adults and children for partial and generalized epileptic seizures. New, noninvasive stimulation devices are under development $[1,2]$. The VNS efficacy has been established, showing a $50 \%$ reduction in epileptic seizure rate in approximately $30 \%$ of patients after one year with

\footnotetext{
* Correspondence: gtimarova@gmail.com; gabriela.timarova@kr.unb.sk; https://www.fmed.uniba.sk/

${ }^{1}$ 2nd Department of Neurology, Faculty of Medicine, Comenius University, Dérer's University Hospital, Limbova str.5, 83305 Bratislava, Slovak Republic Full list of author information is available at the end of the article
}

an increase to approximately $50-70 \%$ after three years, with relatively few patients (less than $10 \%$ ) becoming seizure free [3-5]. Despite more than 20 years of VNS accessibility, the discussion of its safety and efficacy is ongoing. The evidence-based guidelines from the American Academy of Neurology in 2013 [6] emphasized the need for further safety information.

The adverse events (AE) of VNS are of two types: implantation procedure-related and stimulation-related. Surgery-related AE have been reported in $3-22 \%$ of VNS implantations. The most often reported surgery-related $\mathrm{AE}$ are hardware failure in $3.7-16.8 \%$, lead fracture or disconnection in $3.7-13.7 \%$, wound infections in $1.7-$ 
$7.1 \%$, wound hematoma in $0.7-1.9 \%$, transient asystole/ bradycardia up to $1 \%$, left vocal cord palsy, mostly transient, in $1.4-5.1 \%$, and lower facial weakness in $0.2-1.2 \%$ [7-14]. Stimulation-related AE in different studies have been reported to occur in up to $68 \%$ of patients, with $97.8 \%$ of the $\mathrm{AE}$ reported as mild to moderate. The $\mathrm{AE}$ usually appeared immediately after VNS adjustments and disappeared spontaneously over some time or after the adjustment of the stimulation current to the previous level of stimulation [7, 15-17]. Most often reported stimulation-related AE were voice alterations (6-66\%), hoarseness (1.4-64\%), cough (7-45\%), dyspnea (2-25\%), throat pain (4.7-22\%), neck pain and/or tingling and twitching in the neck muscles $(0.5-22 \%)$, dysphagia (13$17.9 \%)$, headache (7-30\%) and chest pain (up to $13 \%$ ). Cases with some pain were reported in 6-30\% of implantations [7, 18-23]. In addition to the VNS side effects reported in population studies, there are rare cases or case series reports of unusual or late-onset stimulationrelated $\mathrm{AE}$ such as parkinsonism [24], late-onset bradyarrhythmia/asystole [25-28], sleep apnea [29, 30], psychosis or mania [31], glossopharyngeal tonsillar pain [32] and pharyngeal dysesthesia [33]. Cases of late-onset trigeminal pain associated with VNS, considering the large number of VNS implantations performed worldwide, are an extremely rare and unexpected event $[34,35]$ (Table 1).

\section{Case presentation}

At the University Hospital Bratislava, Slovakia, we implanted VNS systems in 54 patients with drug-resistant epilepsy not amenable to resection epilepsy surgery between April 2009 and December 2016. Forty-seven of the patients were followed for a long time (one to eight years). The VNS systems were implanted on the left side, and patients had regular follow-up visits with a stepwise increase in stimulation current by $0.25 \mathrm{~mA}$ in 4-8 weeks. The target range of the stimulation current intensity, if tolerated, was between 1.25 and $2.00 \mathrm{~mA}$ with a stimulation frequency $25-30 \mathrm{~Hz}$, pulse width of 250-500 $\mu \mathrm{sec}$ and a duty cycle of $30-21 \mathrm{~s}$ on and 5 to $1.1 \mathrm{~min}$ off, as recommended by the manufacturer.

Two of our patients perceived stimulation-related pain in the upper and lower jaw and teeth ipsilateral to the side of stimulation with a delay of years after device implantation and weeks after last augmentation of the stimulation current intensity, thus mimicking coincidental trigeminal neuralgia to the VNS (Table 2). Both were treated with antiepileptic drugs (AED), which are usually effective in pain treatment (see below), but the AED were not effective in the prevention and control of the pain associated with VNS stimulation.

\section{Case 1}

A 46-year-old man with intractable symptomatic bitemporal epilepsy lasting 33 years, with MRIverified right temporooccipital periventricular heterotopy, was implanted with VNS in November 2012. His seizure frequency before implantation was up to 10 motor seizures with impaired awareness per month and sporadic bilateral tonic-clonic seizures. After implantation, the stimulation current was increased stepwise in 4-8 weeks. He achieved a 50\% reduction in seizures with $2.0-\mathrm{mA}$ stimulation current, $30-\mathrm{Hz}$ frequency, $500-\mu$ sec pulse width, and 30 -s on-time and 1.8-min off-time. Eighteen months after initiation of VNS stimulation, two months since the last increase in the stimulation current, the patient began to complain of sharp, shooting pain in the upper and lower jaw and teeth on the left side, without trigger points or a sensory deficit. The patient underwent $\mathrm{CT}$ scans and detailed dental examination, but no pathological processes were discovered. It was the patient who first noticed that the painful shootings were regular, lasting for tens of seconds with the stimulation on, and that the painless intervals lasted minutes with the stimulation off. The consequent analysis, when we checked the painful and pain-free intervals, ascertained that the pain was associated with the stimulation period of VNS. When the device was off,

Table 1 Characteristics of late-onset trigeminal pain under VNS in reported patients

\begin{tabular}{|c|c|c|c|c|c|}
\hline Author & Type of disease & $\begin{array}{l}\text { Time to } \\
\text { pain onset } \\
\text { from implantation }\end{array}$ & $\begin{array}{l}\text { Time to pain } \\
\text { onset from } \\
\text { last augmentation }\end{array}$ & $\begin{array}{l}\mathrm{SC} \\
(\mathrm{mA})\end{array}$ & Pain localisation \\
\hline Shih [35] & Epilepsy-Tuberous sclerosis & 9 months & 2 months & $1.25^{\mathrm{a}}$ & $\begin{array}{l}\text { Left cheek, mentally retarded } \\
\text { child with unprecise description } \\
\text { of the pain }\end{array}$ \\
\hline \multirow[t]{3}{*}{$\begin{array}{l}\text { Carius and } \\
\text { Schulze-Bonhage [34] }\end{array}$} & $\begin{array}{l}\text { Cryptogenic epilepsy, focal } \\
\text { seizures }\end{array}$ & 5 months & few days & $1.5^{\mathrm{a}}$ & The lower jaw, left \\
\hline & Epilepsy-right frontotemporal & 2 months & 1 month & $0.5^{\mathrm{a}}$ & $\begin{array}{l}\text { The lower jaw and occipital } \\
\text { headache, left }\end{array}$ \\
\hline & Epilepsy- bitemporal & 11 months & 2 weeks & $1.75^{\mathrm{a}}$ & The lower jaw and throat, left \\
\hline
\end{tabular}

SC stimulation current intensity at the time of pain onset

${ }^{a}$ In all patients was stimulation frequency $30 \mathrm{~Hz}$, pulse width 500 usec, duty cycle 30 s on and 5 min off 
Table 2 Characteristics of late-onset trigeminal pain under VNS in the current case series patients

\begin{tabular}{|c|c|c|c|c|c|}
\hline $\begin{array}{l}\text { Sex } \\
\text { (age, years) }\end{array}$ & Type of epilepsy & $\begin{array}{l}\text { Time to } \\
\text { pain onset from } \\
\text { implantation }\end{array}$ & $\begin{array}{l}\text { Time to pain } \\
\text { onset from last } \\
\text { augmentation }\end{array}$ & $\begin{array}{l}\mathrm{SC} \\
(\mathrm{mA})\end{array}$ & Pain localisation \\
\hline Man (46) & $\begin{array}{l}\text { Bitemporal-periventricular } \\
\text { heterotopy }\end{array}$ & 18 months & 2 months & $2,0^{a}$ & $\begin{array}{l}\text { The upper and lower jaw and } \\
\text { teeth, left }\end{array}$ \\
\hline Woman (50) & $\begin{array}{l}\text { Bitemporal- bilateral cystic } \\
\text { hippocampal malformations }\end{array}$ & 4,5 years & 2 weeks & $1,25^{\mathrm{b}}$ & $\begin{array}{l}\text { The upper and lower jaw and } \\
\text { teeth, left }\end{array}$ \\
\hline
\end{tabular}

SC stimulation current intensity at the time of pain onset

a Stimulation frequency $30 \mathrm{~Hz}$, pulse width $500 \mu \mathrm{sec}$, duty cycle $30 \mathrm{~s}$ on/ 1,8 min off

b Stimulation frequency $30 \mathrm{~Hz}$, pulse width $250 \mu \mathrm{sec}$, duty cycle $30 \mathrm{~s}$ on/ 1,8 min off

he was pain-free. The impedance of the electrode was normal. The intensity of the pain was evaluated as 10 on a visual analogous 10-point scale (VAS). The patient had no signs of local current spread to the surrounding tissues (breathing and voice problems, muscle tingling or twitching, no pain in the head, chest or neck). The pain mimicked trigeminal neuralgia type 1 according to Burchiel's classification [36]. According to the seizure diary, where the patient recorded all seizures and painful days, there was a discontinuous course of pain attacks. He was painfree for 1-2 days following every epileptic seizure, with reoccurrence of the pain in the following days. His antiepileptic treatment that time was a combination of lacosamide at $400 \mathrm{mg} /$ day, lamotrigine at $200 \mathrm{mg} /$ day and pregabaline at $300 \mathrm{mg} /$ day. He was treated for concomitant hypertension with perindopril at $4 \mathrm{mg} /$ day, moxonidine at $0.2 \mathrm{mg} /$ day and rilmenidine at $1 \mathrm{mg} /$ day and for anxiety with alprazolam at $1 \mathrm{mg} /$ day. We started adjustments of the stimulation parameters of VNS with a three-month delay due to diagnostic work-up. The patient reported pain relief at a stimulation current of $1,5 \mathrm{~mA}$ and complete resolution at a stimulation current of $0.5 \mathrm{~mA}$. At that time, the frequency of the seizures increased to the original level with a loss of responsivity. At that time, the patient preferred to switch off the device. Six months later, the system was retested. He tolerated a stimulation current up to $1.5 \mathrm{~mA}$ without painful sensations.

\section{Case 2}

A 50-year-old woman with intractable symptomatic bitemporal epilepsy lasting 37 years, with MRI-verified bilateral cystic malformations of mesial temporal lobe structures, was implanted with VNS in April 2011. Her seizure frequency was up to 6 motor seizures with impaired awareness per month and sporadic bilateral tonic-clonic seizures. After VNS implantation, the stimulation current was increased stepwise in 4-8 week intervals up to a $1.0-\mathrm{mA}$ stimulation current intensity, $30-\mathrm{Hz}$ frequency, $250-\mu \mathrm{sec}$ pulse width, 30-s on-time and 3-min off-time. At these stimulation parameters, she was a 50\% responder. Four years later, she overcame status epilepticus. The stimulation current was increased to $1.25 \mathrm{~mA}$ and the duty cycle to $30 \mathrm{~s}$ on and $1.8 \mathrm{~min}$ off. Two weeks later, she began to complain of shooting, sharp pain in the upper and lower jaw and teeth on the left side, without a trigger point or sensory deficit. The intensity of the pain was evaluated as an 8 on the VAS. The pain mimicked trigeminal neuralgia type 1 according to Burchiel's classification [36]. The patient had no signs of local current spread to surrounding tissues. At that time, she was treated with anti-epileptic drugs levetiracetam at $2000 \mathrm{mg} /$ day, lamotrigine at $300 \mathrm{mg} /$ day and carbamazepine at $1200 \mathrm{mg} /$ day. She did not use any other drugs or treatments. The impedance of the electrode was normal. Because of the experience with patient 1 , we immediately checked the relation of the shooting pain to the stimulation period of the VNS and the relation of the pain-free intervals to the off period of the VNS. The pain was recognized as stimulationrelated, and we immediately began the adjustments. The patient reported complete pain resolution at a $1.0-\mathrm{mA}$ stimulation current and continued the VNS.

\section{Discussion and conclusions}

Carius and Schulze-Bonhage [34] reported late-onset trigeminal pain in 3 out of 27 implanted patients (11.1\%), whereas we found it in 2 out of 47 implanted patients longer than one year after implantation (4.3\%). Carius and Schulze-Bonhage proposed mechanisms of central sensitization as the probable cause of the reported pain [34]. Later, Spitz et al. [37] reported a case with a small discontinuity in the lead silicone insulation that led to vocal cord paralysis, impaired breathing and cervical, mandibular, pharyngeal and dental pain. The electrode impedance was normal. The problems started in the early titration period, and the maximum tolerated stimulation current intensity was low $(0.5 \mathrm{~mA}$ maximum). Spitz et al. [37] postulated that the aberrant spread of current through the disrupted insulation likely accounted for other reports of stimulation-related pain (referred trigeminal pain, tonsillar pain, sometimes delayed onset). In other cases, where device malfunction was confirmed, clinical signs of the spread of the 
stimulation current to surrounding tissues were described (hoarseness, vocal cord palsy, distorted breathing, pharyngeal and neck pain, tingling or twitching in the neck muscles and diaphragm dysfunction). The problems typically started after an accident (trauma, puncture, traction, excessive manipulations, tight electrode). In most cases of device malfunctions, the lead impedance is too high or too low [38-41].

In our patients with late-onset jaw and dental pain, the gradual increase in the stimulation current intensity up to $1 \mathrm{~mA}$ and more was uncomplicated. The pain appeared after a pain-free interval from the last adjustment without any accident or trauma and no signs of local current spread. After a 6-month stimulation-free period, patient 1 regained the tolerance for stimulating current up to $1.5 \mathrm{~mA}$, thus pointing to possible desensitization. A unique, intermittent course of stimulation related pain was documented in him with pain relief for 24-48 h following every epileptic seizure. Mechanisms of activity-dependent central sensitization are likely explanations [42]. The nucleus of the solitary tract is the recipient of most afferent sensory fibers of the vagal nerve, but the vagal nerve also sends ipsilateral projections to the spinal trigeminal nucleus (STN). Animal studies have revealed an interesting pattern of trigeminal nociceptive neuronal activation and somatic-visceral trigemino- vagal integration that is mediated by vagal afferents to STN. Central sensitization has been described in the dorsal horn of the spinal cord, as well as in the STN pars caudalis $(\mathrm{Vc})$ and the transition zone $(\mathrm{Vi} / \mathrm{Vc})$ [43]. In an animal experiment, activation of vagal $\mathrm{C}$-fibers was confirmed to not be required to obtain VNS-induced seizure suppression; activation of A- and/or B-fibers seems to be sufficient. These data are clinically important since A- and B-fibers have a much lower activation threshold than $\mathrm{C}$-fibers, thus reducing the amount of current necessary to produce the antiepileptic effects of VNS. Lack of C-fiber recruitment is also important since activation of these fibers would produce central sensitization and undesirable side effects that are not seen in most patients and may have rendered the therapy intolerable in some [44]. The modulatory effects of vagal nerve stimulation on nociception have been studied in animal studies, including the effects in the STN. Both facilitatory and inhibitory effects on neuronal responses to noxious stimuli were observed $[45,46]$. The stimulation parameters favoring pro- or antinociceptive effects of VNS in man are not known [42]. Postictal pain relief was observed in one of our cases. To the best of our knowledge, this is the first case report of late-onset trigeminal pain under VNS revealing a direct link between epileptogenic and pain processing. The postictal state is generally followed by antinociception. Intrinsic neural circuits between dorsal midbrain neurons control seizure activity and the nuclei of the pain inhibitory system elaborating postictal antinociceptive processes. Endogenous opioid-, acetylcholine-, serotonin-, and norepinephrine-mediated systems have been implicated in the organization of tonicclonic seizure-induced anti-nociception [47]. The locus coeruleus represents a key structure in the organization of epilepsy-induced norepinephrine-mediated hypoalgesia, and its lesions suppress the seizure-attenuating effects of VNS [48-50].

With reference to the data accumulated in previous years, late-onset trigeminal pain under VNS stimulation in our patients and patients reported previously can be explained by mechanisms of activity-dependent central sensitization, lead revisions in cases with normal electrode impedance and no signs of local spread of the current seem not to be beneficial. It has to be recognized by physicians, so immediately began to reduce the stimulation current intensity.

\section{Abbreviations}

AE: Adverse events; AED: Antiepileptic drug/drugs; CT: Computed tomography; MRI: Magnetic resonance imaging; STN Vc: Spinal trigeminal nucleus pars caudalis; STN ViNc: Spinal trigeminal nucleus transition zone; STN: Spinal trigeminal nucleus; VAS: Visual analogous scale; VNS: Vagal nerve stimulation

\section{Acknowledgements}

The authors would like to thank Professor Juraj Šteňo, DSc, Chair of the Dept. of Neurosurgery, Faculty of Medicine Comenius University, Dérer's University Hospital Bratislava, Slovakia, for his valuable advice on interpreting the case findings and literature data.

\section{Funding}

No funding was obtained.

\section{Availability of data and materials}

All data generated or analysed during this study are included in this published article.

\section{Authors' contributions}

Both authors, GT and AS conducted the follow-up of patients, data analysis and interpretation. GT prepared the manuscript, which was revised by AS. Both authors approved the final manuscript.

\section{Competing interests}

The authors declare that they have no competing interests.

\section{Consent for publication \\ Written informed consent was obtained from patients for publication of this case series report. A copy of the written consent is available for review by Editor of this journal. \\ Ethics approval and consent to participate \\ This case series report involves two patients. The case series report complies with the Helsinki Declaration, and approval was obtained from the ethics committee of Derer's University Hospital, Bratislava, Slovakia. Written informed consent was obtained from the patients for participation in this study.}

\section{Publisher's Note}

Springer Nature remains neutral with regard to jurisdictional claims in published maps and institutional affiliations. 


\section{Author details}

2nd Department of Neurology, Faculty of Medicine, Comenius University, Dérer's University Hospital, Limbova str.5, 83305 Bratislava, Slovak Republic. ${ }^{2}$ Department of Neurosurgery, Faculty of Medicine, Comenius University, Dérer's University Hospital, Bratislava, Slovak Republic.

Received: 4 April 2017 Accepted: 6 June 2017

Published online: 15 June 2017

\section{References}

1. Howland RH. Vagus nerve stimulation. Curr Behav Neurosci Rep. 2014;1:64-73.

2. Ben-Menachem E, Revesz D, Simon J, Silberstein S. Surgically implanted and non-invasive vagus nerve stimulation: a review of efficacy, safety and tolerability. Eur J Neurol. 2015;22:1260-8.

3. Uthman BM, Reichl AM, Dean JC, Eisenschenk S, Gilmore R, Reid S, et al. Effectiveness of vagus nerve stimulation in epilepsy patients. A 12-year observation. Neurology. 2004;63:1124-6.

4. Elliott RE, Rodgers SD, Bassani L, Morsi A, Geller EB, Carlson C, et al. Vagus nerve stimulation for children with treatment-resistant epilepsy: a consecutive series of 141 cases. J Neurosurg Pediatr. 2011;7:491-500.

5. Van Straten AF, Jobst BC. Future of epilepsy treatment: integration of devices. Future Neurol. 2014;9:587-96.

6. Morris GL III, Gloss D, Buchhalter J, Mack KJ, Nickels K, Harden C. Evidencebased guideline update: Vagus nerve stimulation for the treatment of epilepsy. Epilepsy Currents. 2013;13(6):297-303.

7. Ben-Menachem E. Vagus-nerve stimulation for the treatment of epilepsy. Lancet Neurol. 2002;1:477-82

8. Kahlow H, Olivecrona M. Complications of vagal nerve stimulation for drug-resistant epilepsy. A single center longitudinal study of 143 patients. Seizure. 2013;22:227-33.

9. Horowitz G, Amit M, Fried I, Neufeld MY, Sharf L, Kramer U, et al. Vagal nerve stimulation for refractory epilepsy: the surgical procedure and complications in 100 implantations by a single medical center. Eur Arch Otorhinolaryngol. 2013;270:355-8.

10. Orosz I, McCormick D, Zamponi N, Varadkar S, Feucht M, Parain D, et al. Vagus nerve stimulation for drug-resistant epilepsy: a European long-term study up to 24 months in 347 children. Epilepsia. 2014;55(10):1576-84.

11. Yu C, Ramgopal S, Libenson M, Abdelmoumen I, Powell C, Remy K, et al. Outcomes of vagal nerve stimulation in a pediatric population: a single center experience. Seizure. 2014;23:105-11.

12. Galbarriatu L, Pomposo I, Aurrecoechea J, Marinas A, Agúndez M, Gómez JC, et al. Vagus nerve stimulation therapy for treatment-resistant epilepsy: a 15-year experience at a single institution. Clin Neurology and Neurosurgery. 2015;137:89-93

13. Ghani S, Vilensky J, Turner JB, Tubbs RS, Loukas M. Meta-analysis of vagus nerve stimulation treatment for epilepsy: correlation between device setting parameters and acute response. Childs Nerv Syst. 2015;31:2291-304.

14. Révész D, Rydenhag B, Ben-Menachem E. Complications and safety of vagus nerve stimulation: 25 years of experience at a single center(article). J Neurosurg Pediatrics. 2016;18(1):97-104.

15. Handforth A, De Giorgio CM, Schachter SC, Uthman BM, Naritoku DK, Tecoma ES, et al. Vagus nerve stimulation therapy for partial-onset seizures: a randomized active-control trial. Neurology. 1998;51(1):48-55.

16. Frost M, Gates J, Helmers SL, Wheless JW, Levisohn P, Tardo C, et al. Vagus nerve stimulation in children with refractory seizures associated with Lennox-Gastaut syndrome. Epilepsia. 2001;42(9):1148-52.

17. Rychlicki F, Zamponi N, Trignani R, Ricciuti RA, lacoangeli M, Scerrati M. Vagus nerve stimulation: clinical experience in drug-resistant pediatric epileptic patients. Seizure. 2006;15:483-90.

18. Schachter SC, Saper CB. Vagus nerve stimulation. Epilepsia. 1998;39(7):677-86

19. Rush AJ, George MS, Sackeim HA, Marangell LB, Husain MM, Giller C, et al. Vagus nerve stimulation (VNS) for treatment-resistant depressions: a multicenter study. Biol Psychiatry. 2000;47(4):276-86.

20. De Giorgio CM, Schachter SC, Handforth A, Salinsky M, Thompson J, Uthman $B$, et al. Prospective long-term study of vagus nerve stimulation for the treatment of refractory seizures. Epilepsia. 2000;41:1195-200.

21. Liporace J, Hucko D, Morrow R, Barolat G, Nie M, Schnur J, et al. Vagal nerve stimulation: adjustments to reduce painful side effects. Neurology. 2001;11:885-6.

22. Milby $\mathrm{AH}$, Halpern $\mathrm{CH}$, Baltuch $\mathrm{GH}$. Vagus nerve stimulation in the treatment of refractory epilepsy. Neurotherapeutics. 2009;6(2):228-37.
23. Ramsey RE, Uthman BM, Augustinsson LE, Upton ARM, Naritoku D, Willis J, et al. Vagus nerve stimulation for treatment of partial seizures: 2. Safety, side effects, and tolerability. Epilepsia. 1994;35(3):627-36.

24. Cukiert A, Mariani PP, Burattini JA, Cukiert CM, Forster C, Baise C. Parkinsonism induced by VNS in a child with double-cortex syndrome. Epilepsia. 2009;50(12):2667-9.

25. Amark $P$, Stödberg T, Wallstedt L. Late onset bradyarrhythmia during vagus nerve stimulation. Epilepsia. 2007:48(5):1023-4

26. Iriarte J, Urrestarazu E, Alegre M, Macias A, Gomez A, Amaro P, et al. Late-onset periodic asystolia during vagus nerve stimulation. Epilepsia. 2009;50(4):928-32.

27. Cantarín-Extremera V, Ruíz-Falcó-Rojas ML, Tamaríz-Martel-Moreno A, García-Fernández M, Duat-Rodriguez A, Rivero-Martín B. Late-onset periodic bradycardia during vagus nerve stimulation in a pediatric patient. A new case and review of the literature. Eur J Paediatr Neurol. 2016;20(4):678-83.

28. Singleton AH, Rosenquist PB, Kimball J, McCall W. Cardiac rhythm disturbance in a depressed patient after implantation with a vagus nerve stimulator (article). Journal of ECT. 2009;25(3):195-7.

29. Bhat S, Lysenko L, Neiman ES, Rao GK, Chokroverty S. Increasing off-time improves sleep-disordered breathing induced by vagal nerve stimulation. Epileptic Disord. 2012;14(4):432-7.

30. Papacostas SS, Myrianthopoulou P, Dietis A, Papathanasiou ES. Induction of central-type sleep apnea by vagus nerve stimulation. Electromyogr Clin Neurophysiol. 2007;47(1):61-3.

31. De Herdt V, Boon P, Vonck K, Goossens L, Nieuwenhuis L, Paemeleire K, et al. Are psychotic symptoms related to vagus nerve stimulation in epilepsy patients? Acta Neurol Belg. 2003;103(3):170-5.

32. Duhaime AC, Melamed S, Clancy RR. Tonsillar pain mimicking glossopharyngeal neuralgia as a complication of vagus nerve stimulation: case report. Epilepsia. 2000;41(7):903-5.

33. Ackman C, Riviello JJ, Madsen JR, Bergin AM. Pharyngeal dysesthesia in refractory complex partial epilepsy: new seizure or adverse effect of vagal nerve stimulation? Epilepsia. 2003;44(6):855-8.

34. Carius A, Schulze-Bonhage A. Trigeminal pain under vagus nerve stimulation. Pain. 2005;118:271-3.

35. Shih JJ, Devier D, Behr A. Late onset laryngeal and facial pain in previously asymptomatic vagus nerve stimulation patients. Neurology. 2003;60:1214.

36. Burchiel KJ. A new classification for facial pain. Neurosurgery. 2003;53(5):1164-6.

37. Spitz MC, Winston KR, Maa EH, Ojemann SG. Insulation discontinuity in a vagus nerve stimulator lead: a treatable cause of intolerable stimulationrelated symptoms. J Neurosurg. 2010;112:829-31.

38. Landy HJ, Ramsay RE, Slater J, Casiano RR, Morgan R. Vagus nerve stimulation for complex partial seizures: surgical technique, safety, and efficacy. J Neurosurg. 1993;78:26-31.

39. Kalkanis JG, Krishna P, Espinosa JA, Naritoku DK. Self-inflicted vocal cord paralysis in patients with vagus nerve stimulators. Report of two cases. J Neurosurg. 2002:96:949-51.

40. Rijkers K, Berfelo MW, Cornips EM, Majoie HJ. Hardware failure in vagus nerve stimulation therapy. Acta Neurochir. 2008;150:403-5.

41. Tran Y, Shah AK, Mittal S. Lead breakage and vocal cord paralysis following blunt neck trauma in a patient with vagal nerve stimulator. J Neurol Sci. 2011; 304(1-2):132-5

42. Latremoliere A, Woolf CJ. Central sensitization: a generator of pain hypersensitivity by central neural plasticity. J Pain. 2009;10(9):895-926.

43. Ren $\mathrm{K}$, Dubner $\mathrm{R}$. The role of trigeminal interpolaris-caudalis transition zone in persistent orofacial pain. Int Rev Neurobiol. 2011;97:207-25.

44. Krahl SE. Vagus nerve stimulation for epilepsy: a review of the peripheral mechanisms. Surg Neurol Int. 2012;3(S1):47-52.

45. Bossut DF, Maixner W. Effect of cardiac vagal afferent electrostimulation on the responses of trigeminal and trigeminothelamic neurons to noxious orofacial stimulation. Pain. 1996;65:101-9.

46. Lyubashina OA, Sokolov AY, Panteleev SS. Vagal afferent modulation of spinal trigeminal responses to dural electrical stimulation in rats. Neuroscience. 2012:222:29-37.

47. Coimbra NC, Castro-Souza C, Segato EN, Nora JE, Herrero CF, Tedeschi-Filho W, et al. Post-ictal analgesia: involvement of opioid, serotoninergic and cholinergic mechanisms. Brain Res. 2001;888:314-20.

48. Krahl SE, Clark KB. Vagus nerve stimulation for epilepsy: a review of central mechanisms. Surg Neurol Int. 2012;3(4):255-9.

49. Felippotti TT, Ferreira CMR, Freitas RL, Oliveira RC, Paschoalin-Maurin T, Coimbra NC. Paradoxical effect of noradrenaline-mediated 
neurotransmission in the antinociceptive phenomenon that accompanies tonic-clonic seizures: role of locus coeruleus neurons and a2- and $\beta$ noradrenergic receptors. Epilepsy Behav. 2011;22:165-77.

50. Freitas RL, Ferreira CMR, Ribeiro SJ. Intrinsic neural circuits between dorsal midbrain neurons that control fear-induced response and seizure activity and nuclei of the pain inhibitory system elaborating postictal antinociceptive processes: a functional neuroanatomical and neuropharmacological study. Exp Neurol. 2005;191:225-42.

Submit your next manuscript to BioMed Central and we will help you at every step:

- We accept pre-submission inquiries

- Our selector tool helps you to find the most relevant journal

- We provide round the clock customer support

- Convenient online submission

- Thorough peer review

- Inclusion in PubMed and all major indexing services

- Maximum visibility for your research

Submit your manuscript at www.biomedcentral.com/submit 